\title{
Valproic Acid-Expanded Umbilical Cord Blood-derived CD34-positive Cells
}

National Cancer Institute

\section{Source}

National Cancer Institute. Valproic Acid-Expanded Umbilical Cord Blood-derived CD34positive Cells. NCI Thesaurus. Code C157453.

A preparation of umbilical cord blood (UCB)-derived CD34-positive cells treated with valproic acid (VPA) with potential use in hematopoietic stem cell transplant (HSCT). Upon positive immunomagnetic selection of CD34-positive cells from UCB units, CD34-positive cells are expanded in culture with stem cell factor (SCF), FMS-like tyrosine kinase 3 lig and (Flt3L), thrombopoietin (TPO), and interleukin-3 (IL-3), treated with VPA, and infused into the patient. VPA, a histone deacetylase inhibitor (HDACi), may induce epigenetic changes in UCB hematopoietic stem cells (HSCs), resulting in expansion of CD34-positive cells enriched in short term (ST), intermediate term (IT), and long term (LT) marrow repopulating cells (RCs), which are capable of sustained hematopoietic eng raftment following transplantation. Further, VPA-expanded UCB stem cells may shorten the time to neutrophil and platelet recovery and maintain long-term hematopoietic and immune reconstitution compared to untreated UCB grafts. 